on the same causes that influence us in determining that of the mother.

Puchelt states, that-

21 children died before delivery;

$2-$ after delivery;

7 were born alive;

while in 2 , the result is not stated.

In Dr. Merriman's cases, the still-born children amounted to 16 , and those born alive to 4 .

Mrs. T-, a delicate, strumous-looking woman, twenty-nine years of age, was under my care for twelve months before her marriage, which took place eight months since. Her friends had previously consulted me with respect to the propriety of the proposed union, as, from a considerable spinal curvature, they were afraid deformity of the pelvis existed. About three months previous to her marriage, she requested my opinion respecting a tumor iu her left side, which, upon careful examination, I pronounced ovarian; and notwithstanding that $I$ advised her to put off her wedding for a time, she married secretly, and in four weeks became pregnant. Nausea, sickness, and the other accompaniments of the pregnant condition, were very distressing; and the two former yielded only to two-drop doses of creasote. As pregnancy advanced, the ovarian tumor also increased; so that, by the time she had reached the eighth month, I thought it prudent to institute a careful external and internal examination, in order to ascertain the size, consistence, and mobility of the tumor, and so determine what were the chances of safe delivery, or whether premature labor should be induced. There existed a lateral obliquity of the uterus, caused by the projection of the ovarian tumor, which was of the size of the head of a seven-months' child; it was moveable, and, externally, no fluctuation could be detected. Upon making a vaginal examination, the tumor could be felt in the upper and left side of the vagina, easily moved ; the impression of indistinct fluctuation could be conveyed to the examining finger, when firm pressure was made on the tumor externally. The dimensions of the pelvis appeared to be normal ; and after duly weighing all the circumstances of the case,.I decided upon permitting her to go on to the full term of gestation. The mobility of the tumor led me to hope I should succeed in placing it above the pelvis, out of the reach of pressure; whilst the evidence I had of fluctuation caused me to anticipate, that should I not succeed in this, I might readily let out the fluid contents of the cyst per vaginam, and thus, in a great degree, remove the cause of obstruction. In due time, her labor came on; its first stage was protracted and tedious, from two causes-the early discharge of the liquor amnii, and the obliquity of the womb itself; but as the labor progressed, I was enabled, with a little management, to raise the tumor above the brim of the pelvis. The labor pains, which were frequent and violent, soon forced the head into the pelvic ca'vity, and the labor was completed after nine hours' duration, the child being born alive. On the third day after delivery there was some tenderness over the region of the tumor, accompanied with symptoms of febrile excitement; for which, leeches, warm cataplasms, a purgative, and some antimonial saline medicine, were ordered; these symptoms quickly subsided, and in three weeks from the time of her accouchemen ${ }^{t}$ she was out of her bedroom. After she had suckled her child for three months, her constitutional powers were evidently beginning to fail ; but no persuasion could induce her (by nature a very obstinate woman) to feed her child. The consequence was, that, with the impairment of her general health, the ovarian tumor began to enlarge; so that in eight months from the period of her confinement she was as large as before her delivery. After the usual palliative remedies had been tried, paracentesis was had recourse to in eleven and a half months from the time of delivery. Fur two years and a half she lingered out a miserable existence, and died of peritonitis, after undergoing the operation of paracentesis for the fifth time. No post-mortem examination was allowed; but I am inclined to believe the other ovarium was also diseased, as there was a tumor in its locality, and the patient had not menstruated since her confinement.-Dr. Lever, in Guy's Hospital Reports.

\section{SUSPECTED POISONING.}

TO THE EDITORS OF THE PROVINCIAL MEDICAL

$$
\text { JOURNAL. }
$$

Gentlemen,-In my opinion Dr. Johnson, of 101, Drury-lane, met with injustice at a late coroner's inquest, because, if I had been a juryman, I could not have conscientiously agreed to any verdict but one of "natural death."

Mr. Taylor is reported to have said, first, "I can tell whether or not there was too much opium in the mixture ;" and, secondly, "I chiefly relied on the quantity of spirit ;' ' which two assertions are, in my imagination, so far from being in accordance with each other, as to make him contradict himself; therefore, I think either his evidence has not been given correctly in the "Morning Post," or he has spoken so absurdly as to show that he is a very incautious and unsafe chemist to be a witness before a jury in a criminal prosecution.

There are but few rules which have not exceptions, but, to speak more than generally, almost invariably, if full doses of opium be indicated for a child of four or five years old, and the same quantity only be administered as that child took, it will be very iner? practice. Supposing, for the sake of argument, this child had died from the effect of opium, it might be said, "There are six children at that age in England whose constitutions, under such circumstances, would not bear such doses of paregoric ;" but it might be said in reply, "Still, all the other children in England (without such idiosyncrasy) would be neglected by, and might die in consequence of, such inefficient treatment."

The apothecary probably misled the jury by saying, "My evidence will be fully borne out by one of the first chemists of the day," instead of saying, "Sup. ported by one who, imagining and supposing, will profess to know more than he will prove that he does know."

He said, "the only morbid appearances were those of enlargement of the heart, inflammation in the bronchial tubes, and some air which had escaped into the cellular membrane of the lungs," and from his further evidence I conclude that the brain did not show the usual appearance produced by an over-dose 
of opium, yet " he was decidedly of opinion that the child's death was caused by opium."

Dr. Babington also thought the remedy, not the disease, produced death. He tells us the heart disease arose from "a difficulty of propelling blood," but does not say how he knows that the enlargement of the heart was not congenital. It should not become fashionable to punish one man upon the speculative opinions and theories of other men. We suppose that, generally speaking, when there are doubts, the accused party will have the benefit of them; but, as far as I am able to judge from experience, this verdict was given against the party accused, under false impressions, not upon facts. And if the judgment of the medical men of England were taken by vote, whether the evidence given at that inquest or these remarks and opinions are the most reasonable, I should not fear the result.

$$
\begin{aligned}
& \text { Remaining, Gentlemen, } \\
& \text { Yours, \&c., }
\end{aligned}
$$

W. Allison.

East Retford, April 12, 1813.

\section{TREATMENT OF MEDICAL OFFICERS OF UNIONS.}

TO THE EDITORS OF THE PROVINCIAL MEDICAL JOURNAL.

Gextlenen,-Aware as you already are of the inadequate salaries in general allowed to union medical officers for their laborious attendance on the sick poor, perhaps the following fact will be found altogether if not entirely without a parallel.

I have been the medical officer to a district in the Axbridge union for the last four years, and made during that period 2,763 visits to paupers, many living five or six miles, and the nearest one and a half from my residence, besides supplying them with necessary medicines. For this I have been paid only $£ 133$. On receiving a letter from the clerk of the board, respecting my accepting it for another year, I declined, unless the salary was increased; many of the guardians were so disposed, but on one of them stating a friend of his, Mr. Millard, would accept it without any addition, it was transferred to him, thus entirely setting aside the regulations of the poor-law commissioners, issued in March, 1842, as the only qualification this gentleman possesses is a certificate from the Apothecaries' Company in London, and he has been in practice not three years in this part of the country (or any other to my knowledge).

Having lately reduced a fractured leg, I considered myself entitled to a fee of three guineas, which was refused by the board on the ground of my election having taken place prior to the appearance of the new regulations-a mere subterfuge, in my opinion, to evade payment.

Should you think proper to insert the above in your valuable and widely-circulated Journal, you will oblige

Your obedient servant,

W. H. Parsley, M.R.C.S.L.

Banwell, April 3, 1843.

\section{ASSURANCE OFFICE FEES.}

TO THE EDITORS OF THE PROVINCIAL MEDICAL JOURNAL.

Gentlemen,-I have much pleasure in informing you that the following resolution has been adopted by the medical men of this town, Modbury, and Dartmouth, upon the subject of a fee for a medical certificatc from insurance companies.

I am, Gentlemen,

Your obedient servant, W. C. Ford, Hon. Sec.

"We, the undersigned medical men, pledge ourselves not to answer the inquiries of insurance companies unless accompanied by a fee of one guinea, being a resolution in unison with the British and Shrewsbury Medical Associations."

W. C. Ford, surgeon, Kingsbridge.

W. Toms, ditto ditto.

John Ellio't, ditto ditto.

F. D. Pearse, ditto ditto.

F. S. Cornish, ditto ditto.

J. P. Stone, ditto, Chillington.

C. Cross, ditto ditto.

Richard Gellard, ditto, Selcombe.

W. B. Avent, ditto, Modbury.

W. S. Langworthy, ditto ditto.

George Langworthy, ditto ditto.

W. F. Langworthy, ditto ditto.

James Gest, ditto ditto.

R. Birrough, ditto, Dartmouth.

J. Puddicombe, ditto ditto.

J. Puddicombe, jun., ditto ditto.

Kingsbridge, Devon, April 9, 1843.

\section{APPOINTMEN'T OF CERTIFYING SURGEONS}

UNDER THE NEW FAC'TORY BILL.

To THE EDItors of THE PROVINCIAL MEDICAL JOURNAL.

Gentlenes,-I enclose, for insertion in your Journal, a copy of the memorial addressed to Sir James Graham, by the medical practitioners of this town and neighbourhood, on the subject of the appointment of certifying surgeons under the new Factory Biil. A petition to the same effect will be presented to the House of Commons. Both documents have received the signatures of a great majority of the medical men in this town, including the names of those of the highest standing and respectability.

I have the honor to be, Gentlemen, Your obedient servant, J. INGHAM IKIN.

Leeds, April 17, 1843.

To the Right Hon. Sir James Graham, M.P., Her Majesty's Secretary of State for the Home Department.

The memorial of the undersigned surgeons and apothecaries, practising in Leeds and its neighbourhood,

Humbly sheweth,

lst. That your memorialists observe with regret and dissatisfaction the insertion of clauses in the new Factory Bill, giving the nomination and appointment of certifying surgeons to the inspectors. 